\title{
WHO records slight blip in downward trend in Ebola incidence
}

\section{Anne Gulland}

London

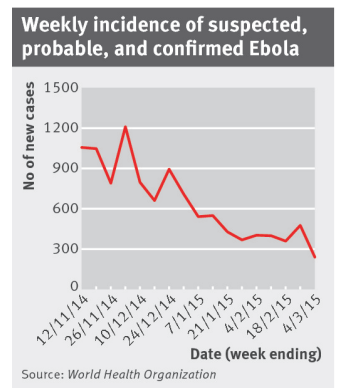

A slight increase in the number of new cases of Ebola virus disease in February has caused only a small blip on the downward curve of the graph since the epidemic peaked at the beginning of December.

Weekly incidence peaked in the week ending 3 December 2014, when there were 1210 new confirmed, suspected, and probable cases. By contrast, in the week to 4 March the World Health Organization reported only 240 confirmed, suspected, and probable cases, of which 132 were confirmed. So WHO's dramatic warning given in October that the number of new cases could reach 10000 a week by December was never realised.

The roots of the current epidemic go back to December 2013, when the first case was reported in Guinea. It was not until 23 March 2014, however, that the first indications of an epidemic were reported. On the disease outbreak news page of its website WHO reported that it had been informed by Guinea's Ministry of Health of a "rapidly evolving outbreak of Ebola virus disease." At that point there had been a total of 49 cases and 29 deaths.

Over the next few months the number of cases rose rapidly, and the disease spread to Liberia and Sierra Leone, with 710 more cases reported by 7 July, bringing the total to 759 . But it was not until 8 August that WHO declared the disease an international public health emergency. ${ }^{2}$ By this time the disease had spread to Nigeria, and there were a further 1020 cases, bringing the total up to 1779 .

Over the next month the number of cases proliferated, and the charity Médecins Sans Frontières warned the United Nations that it could not battle the outbreak alone and called for the deployment of the military. ${ }^{3}$ By 4 September there were a further 1906 cases, bringing the cumulative total to 3685 .
In that month, the international effort to combat the disease expanded, with Cuba pledging 165 health workers and the United States announcing the deployment of 3000 army personnel. ${ }^{4}$ By 3 October the outbreak in Nigeria seemed to be over, but there was a fatal case in the US, ${ }^{6}$ and a nurse became infected in Spain, ${ }^{7}$ prompting widespread media coverage of the epidemic around the world.

The situation began to look increasingly desperate, with WHO issuing its warning in October that if the number of cases continued to increase at the current pace there could be 10000 new cases a week by December. ${ }^{8}$ By 5 November a cumulative total of 13042 cases had been reported.

In October and November vaccine and therapy trials were beginning to be discussed, ${ }^{9}$ and the UK's first army built Ebola treatment centre was opened in Sierra Leone.

But, although people did not realise it at the time, the epidemic was reaching its climax. The incidence peaked on 3 December, after which numbers of new cases started to fall.

By 7 January the weekly incidence was running at 541 cases and fell during that month to 368 . Numbers climbed slightly during February, with the weekly total of new cases reaching 476 on 25 February, but overall the figures were about 700 fewer cases than at the epidemic's height.

For all The BMJs articles covering the Ebola epidemic go to thebmj. com/ebola.

World Health Organization. Global alert and response (GAR): Ebola virus disease in Guinea. 23 Mar 2014. www.who.int/csr/don/2014_03_23_ebola/en.

2 Hawkes $\mathrm{N}$. Ebola outbreak is a public health emergency of international concern, WHO warns. BMJ 2014;349:g5089.

3 Torjesen I. World leaders are ignoring worldwide threat of Ebola, says MSF. BMJ 2014;349:95496.

4 Gulland A. Cuba pledges 165 health workers to treat Ebola patients in Sierra Leone. BMJ 2014;349:g5647.

5 McCarthy M. US plans to deploy 3000 army personnel to tackle Ebola in west Africa. BMJ 2014;349:g6145.

6 McCarthy M. Liberian man being treated for Ebola in Texas dies. BMJ 2014;349:95980. Gulland A. Spanish authorities investigate how nurse contracted Ebola. BMJ 2014;349:g6120.

8 Gulland A. WHO hopes Ebola incidence will decline after peaking in December. BMJ 2014;349:g6255.

9 Gulland A. Vaccine tests to begin in Ebola countries this year. BMJ 2014;349:g6466. 